\title{
The Relationship between E-Marketing Strategy and Performance: A Conceptual Framework in a Web Context
}

\author{
Carmen Lages \\ Assistant Professor of Marketing \\ ISCTE Business School - Lisbon, Portugal, Av. das Forças Armadas 1649-026 \\ Lisboa,Portugal \\ e-mail: carmen.lages@iscte.pt url: http://home.iscte.pt/ chfl/
}

Luís Filipe Lages

Assistant Professor of Marketing and International Business,

Universidade Nova de Lisboa, Faculdade de Economia, Campus de Campolide, 1099-

032 Lisboa, Portugal.

e-mail: Iflages@fe.unl.pt url: http://docentes.fe.unl.pt

Paulo Rita

Associate Professor of Marketing

ISCTE Business School - Lisbon, Portugal, Av. das Forças Armadas 1649-026 Lisboa, Portugal.

e-mail: paulo.rita@iscte.pt url: $\underline{w w w . i s c t e . p t / \sim r i t a}$

2004

This research was funded by a research grant from the 6th European Framework Program, Specific Support Action-CoCombine. Luis Filipe Lages is grateful to "Nova Égide” and Carmen Lages and Paulo Rita acknowledge “UNIDE/ISCTE”. 


\title{
The Relationship between E-Marketing Strategy and Performance: A Conceptual Framework in a Web Context
}

\begin{abstract}
While building on the contingency theory, this paper proposes a conceptual framework that links five factors: a) internal forces, b) external forces, c) past web and firm performance, d) current web and firm performance, and e) e-marketing strategy in terms of the strategy defined for the 4Ws (Web-Design, Web-Promotion, Web-Price, and WebCRM). Future research is encouraged to build on this framework to test how internal and external forces of the firm, along with its past performance, influence the determination of e-marketing strategy and how in turn, e-marketing strategy impacts on performance at the web and firm levels.
\end{abstract}

\section{INTRODUCTION}

As of September 2003, 604 million people worldwide had internet access (www.cyberatlas.com). The Internet is assumed to be an important channel for marketing and distribution of products and services. This is, among other things, due to the costeffectiveness of the Internet and the convenience for customers. With the Internet marketers can reach out to a broad customer base, locate target customers, identify their needs and communicate with them at a relatively low cost. The Internet provides an opportunity for market testing and optimization. Increasing digitalization will make it progressively easier to experimentally alter particular aspects of a business and quickly observe how customers respond (Wyner 2000). 
Since the Web allows access to a plethora of information on different products, the organization must encourage the potential consumer to use the Web site as both an information tool as well as a purchase option. This combination of information search and purchase process is an advantage over traditional retailing as online consumers have stated that personalized targeting is a reason they shop online. When consumers are more involved in the buying process it significantly improves brand recognition and recall.

\section{RESEARCH OBJECTIVES}

There are three main objectives of this research, the first of which is to extend our understanding of the contingency theory, particularly in an e-marketing context. This is accomplished by presenting a more comprehensive understanding of the simultaneous links among the internal and external forces of the firm, e-marketing strategy, and performance. Earlier marketing research has focused only on single relationships among these variables (e.g., the relationship between strategy and performance or the relationship between contingency forces and strategy), while rarely considering their simultaneous effects. A contingency approach allows for a multi-faceted approach to the phenomenon. We also advance past work on marketing strategy, which has traditionally focused on a single marketing-mix element, to consider the full marketing mix in a web context.

The second objective of this work is to consider the role of past performance on marketing strategy formulation and on current performance in an internet context. Historically, marketing strategy formulation is viewed as an antecedent to performance outcomes (Lages 2000). A review of the top journals in strategy and organizational behavior indicates that $79 \%$ of the articles incorporating performance have cast it as a 
dependent variable, while only $9 \%$ of the studies have used it as an independent variable (March and Sutton 1997). Past performance can be a critical variable in the determination of e-marketing strategy, and the evaluation of current period performance. When firms experience poor performance they are more likely to search broadly for information and conduct in-depth analyses of their surrounding environments. In contrast, a good performance might promote more relaxed and effortless strategic decisions (Dutton and Duncan 1987; Lages and Montgomery 2001, Lages and Montgomery, forthcoming), as the firm may also become less critical about previous decisions (Fredrickson 1985), contributing to a narrow focus and preoccupation with the factors that contribute to performance at the expense of remaining responsive to all possible internal and external factors.

The third objective is to study how an articulated approach to four critical e-marketing strategy tasks - the 4 Ws (Web-Design, Web-Promotion, Web-Price and Web-CRM) relates to current performance. Figure 1 presents the conceptual framework that incorporates past performance, internal and external forces of the firm, e-marketing strategy, and current performance. 
Figure 1: A contingency framework of the relationship between e-marketing strategy and performance

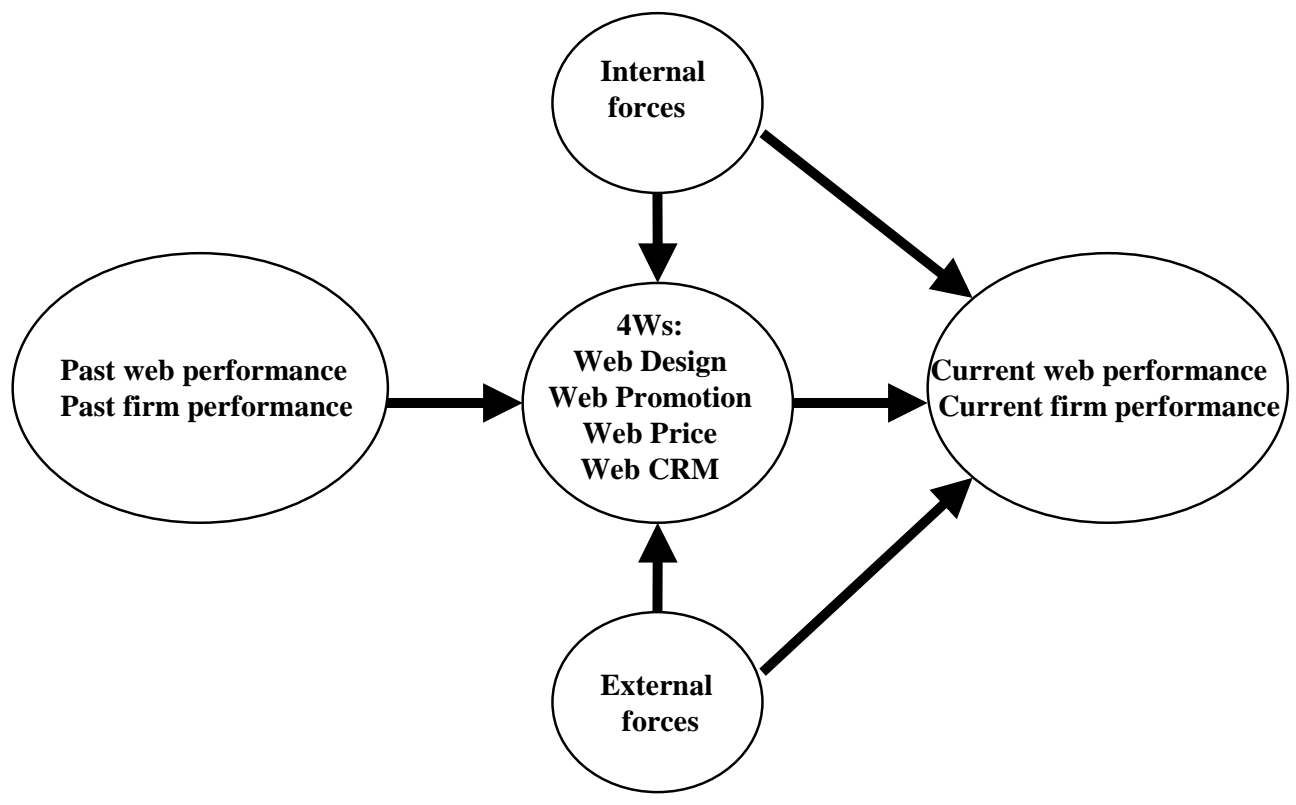

THEORETICAL BACKGROUND

This paper is based in the contingency theory, which has its early roots in the general systems theory (Boulding, 1956; Von Bertalanffy, 1951) and in the behavioral theory of the firm (Cyert and March, 1963; March and Simon, 1958; Simon, 1957). Over the last four decades this perspective has been widely accepted in the field of marketing research (see: Zeithaml et al. 1988). This theory defends that the best strategy across situations does not exist. Performance levels result from the co-alignment among strategy and the firm's context (i.e., the internal and external forces). Each strategy may be, or not, the best depending on the nature of the contingent forces. While building on the contingency approach, we propose the following research propositions (see Figure 1).

Proposition 1: Depending on the nature of the internal factors, performance might be:

- $\quad$ positively or negatively affected by these factors; 
- directly affected by these factors; $\underline{\text { and }}$

- indirectly affected by these factors through their influence on e-marketing strategy.

Proposition 2: Depending on the nature of the external factors, performance might be:

- positively or negatively affected by these factors;

- directly affected by these factors; $\underline{\text { and }}$

- indirectly affected by these factors through their influence on e-marketing strategy.

Proposition 3: There is a relationship between performance levels in the past year and performance levels in the current year. This relationship might be:

- positive or negative depending on the nature of the contingent forces;

- direct; $\underline{\text { and }}$

- indirect, through the influence of past performance on e-marketing strategy.

Based on the marketing literature, we now propose some elements to operationalize internal and external forces, e-marketing strategy, and performance (see Figure 1).

\section{Internal Forces}

The marketing literature suggests a variety of internal forces, i.e., corporate forces are relevant for e-marketing strategy and performance.

Organizational Innovation. Organizational innovation is a function of management that seeks to create new solutions for existing or potential problems. Many studies have demonstrated the link between innovation and business performance (Damanpour and Evan 1984). Today's intensification of competition and of environmental uncertainty gives innovation an increasingly important role not only for growth but also for survival 
(Grønhaug and Kaufmann 1988). The concept of organizational innovation presents a dichotomy: technical Vs administrative (Daft, 1982; Dalton, 1986; Damanpour, 1991). Accordingly Damanpour (1991), administrative innovations involve organizational structure and administrative process; they are indirectly related to the basic work activities of an organization. Technical innovations "pertain to products, services and production process technology; they are related to basic work activities and can concern either product or process" (Damanpour, 1991: 560). It is expected that technical innovation is strongly associated with the importance of e-marketing strategy within a firm.

Organizational bureaucratization. Organizational bureaucratization is the degree to which procedures are required to be formalized. The contingency theory argues that bureaucratic structures - that rigidly institutionalize previous lessons from prior experience - can improve performance under stable conditions, but more organic structures are necessary in turbulent conditions (Lawrence and Lorshch, 1967; Mintzberg, 1979). Either way, it seems reasonable to expect that the degree of bureaucratization of an organization developing e-marketing strategy is related with performance.

Centralization. Centralization refers to the degree in which authority for decision making concentrates at the highest levels of the organization (Dewar and Werbel, 1979). There are two schools of thought about the impact of centralization on marketing strategy making. One traditional school argues that centralization leads to a better strategy making, suggesting that in centralized organizations the planning processes use specialized instruments, techniques and personnel (Hofer and Schendel, 1978). In 
contrast, another school defends that centralization is associated with more political activity (Eisenhardt, 1989). From this perspective, centralization imposes time limits to decision making, which consequently give less emphasis to situation analysis and comprehensive development of e-strategy making (Miller, 1987).

Market orientation. It has been shown that, in general, market orientation is positively related with various business performance measures (e.g. Jaworski and Kohli 1993; Selnes, Jaworski and Kohli 1997). Hence, it is expected that this situation also occurs in an e-marketing context. According to Kohli and Jaworski (1990: 6), market orientation "is the organization wide generation of market intelligence pertaining to current and future customer needs, dissemination of the intelligence across departments, and organization wide responsiveness to it”. Deshpandé and Farley (1996:13) define market orientation as "the set of cross-functional processes and activities directed at creating and satisfying customers through continuous needs-assessment”. Kohli and Jaworski (1990) conceptualized market orientation as an organized set of marketing activities. A market orientation, as a corporate culture, characterizes an organization's disposition to deliver superior value to its customers continuously. Scholars of market orientation consider a market-oriented corporate culture as a significant factor in achieving corporate performance. It has been shown that market orientation, is, in general, positively related with various business performance measures (Jaworski and Kohli 1993; Selnes, Jaworski, and Kohli, 1997). Narver and Slater (1990: 21) suggested that market orientation consists of three behavioral components, each involved in collecting, disseminating and responding to information: customer orientation, competitor orientation and inter- 
functional coordination, that constitute the activities of market information acquisition and dissemination and the coordinated creation of customer value.

Customer orientation: under the perspective of the marketing concept - that argues for placing clients' interests first - a customer orientation is one of the most fundamental aspects of organizational culture (Lawton and Parasuraman, 1980). Following the organizational learning theory, Huber (1991) and Sinkula (1994) see the customer knowledge process as consisting of three sequential aspects: customer information acquisition, interpretation and integration.

Competitor orientation: a focus on the client alone can take the institution to a reactive cycle, instead of proactive, if it does not equally consider the competitors' actions (Day and Wensley, 1988). A competitor-oriented company seeks to evaluate its strengths and weaknesses in relation to its main competitors, with the objective of maintaining or gainning advantage. Competitor knowledge process is the process of information collection about the strengths and weaknesses of the competition, analysis and integration in decision making. Like customer knowledge process, this process involves three behavioral aspects: competitor information acquisition, interpretation and integration. De Geus (1988:4) argues that in the future the only competitive advantage of a company will be its ability to know about the competition quicker than its rivals.

Inter-functional coordination: Felton (1959) insists that for the marketing concept to be implemented, there must be integration of the other organization's functions with marketing. Communication among the various functions of the company helps in responding to the client, which is harder to achieve if the various departments work within their routines without a common objective (Zaltman, Duncan and Holbek, 1973). 
Finally, at the internal level all firms are dependent on the availability of resources to develop appropriate strategies. As increasing levels of resources are committed to the emarketing activity, the firm will be better able to improve its planning procedures, implement more adaptive e-strategies and achieve its goals. And if one considers that the long-term failures and successes of the firm is a function of its short-term actions (Lages and Lages 2004), it is clear that understanding the impact of resource availability on the development of e-marketing strategies can yield valuable insights into improving performance.

\section{External Forces}

Market Turbulence. Market turbulence is the degree of change in the client composition and client preferences (Jaworski and Kohli 1993). Market turbulences are typically generated by the heterogeneity of consumer preferences (Han et al. 1998). Korgaonkar and Wolin (1999) studied web users' motivations and concerns in relation to different types of usage. They found that web users' motivations and concerns correlate significantly with the number of hours per day spent on the Web, the percentage of time spent on the Web for both personal and business purposes, and the users' purchasing behavior. The findings suggest the presence of seven motivations and concerns regarding web use: social escapism, transaction-based security and privacy, information, interactive control, socialization, nontransactional privacy, and economic motivation.

Technological Turbulence. Technological turbulence is the degree of change associated with new product technologies (Glazer and Weiss 1993). Technology change refers to the speed with which the technology is developed in a market product. On one hand, some authors (Day and Wensley 1988; Narver and Slater 1990) argue that when technologies 
change quickly, it is imperative to the companies to interact with clients, because client preferences and needs can provide directions in a product market. On the other hand, Jaworski and Kohli (1993) suggest that the importance of information from the client is lower because the client knows little about the emergent technologies.

Competitive Intensity. Competitive intensity is the degree of competitive force in a product market. In conditions of intensive competition, collection of information about competition can help e-firms to better anticipate the changes in competitor strategies for new products and reduce market unpredictability. Neglecting competition can damage the position of the company in the market. With intensive competition, product advantage and market share become more volatile (Day and Wensley 1988).

\section{Web-Marketing Strategy}

Strategy as a general direction of the company reflects its response based on information from the environment (Jennings and Zandbergen 1995) and that can explain the magnitude of the relationship between performance measures and a specific marketing response from the company (as for example market orientation). Walker and Ruekert (1987) argue that strategic orientation, performance in specific dimensions and marketing activities have a contingent relationship: the companies choose a type of strategy to obtain excellency in particular dimensions of performance, and execute each strategy by choosing marketing activities. The current study will operationalize web strategy using four main constructs, in other words, will use the 4Ws: Web-Design, Web-Promotion, Web-Price and Web-CRM (Figure 1). E-marketing strategy involves using electronic methods and affects traditional marketing in two ways. First, it increases efficiency in established marketing functions. Second, the technology of e-marketing transforms many 
marketing strategies resulting in new business models that add customer value and/or increase company profitability (Strauss and Frost, 2001).

Web-Design. Attitude towards the web site has been researched as an important measure for how well a web site is doing. Chen and Wells (1999) found that entertainment, informativeness and organization profiles of web sites are useful descriptive dimensions, which in their study have correlated with attitude towards the site.

Web-Promotion. Stevenson et al. (2000) have conducted research on the type of background that is most appropriate for positively affecting advertising effectiveness. Bruner and Kumar (2000) further explored the advertising hierarchy of effects as measured by several common attitude measures, namely attitude towards the ad, attitude towards the brand, attention to the commercial, purchase intention, and its antecedents in the context of the web. Web experience was found to play an important role along with web page complexity and interestingness on attitude towards the web site, which in turn had significant effects on the web advertising hierarchy of effects. Their findings suggest that simpler web page backgrounds are more effective than more complex ones.

Web-Price. The advent of the Internet as a new medium for buyer-seller interaction is changing the issue of price for both customers and suppliers in an unprecedented way. On the one hand, there are Internet dynamics that flatten the customer value pyramid (defined by the value of the customer to the firm) because of technology that facilitates customer search, customer control over transactions, the provision of means by which the customer can make rather than take the price, and a return to one-on-one negotiation. On the other hand, firms may create customer-switching barriers, differentiate on other 
dimensions of the purchase decision and reduce transaction costs (Pitt et al. 2001). The fundamental value of the Internet lies not in lowering prices or making them consistent but in optimizing them in three ways. First, the Net allows companies to set and announce prices with greater precision since different prices can be tested easily, and customers' responses can be collected instantly. Second, as it is so easy to change prices on the Internet, companies can adjust prices in response to even small fluctuations in market conditions, customer demand, or competitors' behavior. Third, companies can use the clickstream data and purchase histories that they collect through the Internet to segment customers quickly and offer segment-specific prices or promotions immediately. (Baker et al., 2001)

Web-CRM. The Web can be used to establish direct marketing channels between firms and consumers (Lau et al., 2001). Through data mining tools, it is possible to make use of the personal information on a visitor's web site and identify his or her interests and needs. Based on such understanding, firms can send e-mail messages and offer service packages especially designed for a potential customer, based on the marketer's assessment of the individual's interests. Because of increased competition among actors offering their products and services on the Internet, generating revisits to companies' web sites has become a major challenge for many companies. In order to generate revisits, substantial amounts of resources are used in efforts to develop superior web sites that attract customers (Supphellen and Nysveen 2001). By structuring one’s thinking about a form's relationship with its customers, companies can identify their strengths and highlight areas in need of improvement (Picolli et al. 2001). 


\section{Performance}

A key concern of this study is related to the conceptualization and measurement of performance. Overall the literature suggests that a multidimensional scale is required. One approach that is increasingly relied upon is the aggregation of various performance measures into a single measure of performance. We incorporate this approach here by considering firm performance as well as web site performance evaluation (Chakraborty et al. 2002).

Firm Performance - Firm performance is a well-established measure in the marketing literature. We will measure it through sales volume, profitability and market share for the current period (current firm performance), and perceived satisfaction with these measures when considering the previous year (past firm performance).

Web-performance - The identification of current market position in the web is an essential issue. Although many e-commerce companies collect cost and usage data about their Web sites, few of them understand in any detail how well such information measures their sites' performance or how this performance compares with that of competing sites. However, since the year 2000 investors have been insisting, if not on profits, at least on objective measures of a site's success in attracting, converting and retaining customers. Most measures of web-performance track variations in traffic-page views, advertising impressions served, unique users, and so on. But the foundation of long-term performance is lifetime customer value: the revenue customers generate over their lives, less the cost of acquiring, converting, and retaining them. A recent McKinsey study (Kemmler et al., 2001) shows that while the performance of Internet retailers is improving, most media and content sites are going down. Thus, e-tailer sites are creating 
significantly more value than content sites. The latter need to continue their search for a winning business model in the face of rising acquisition costs and slumping ad revenues.

\section{CONCLUSION AND RESEARCH IMPLICATIONS}

This conceptual study intends to add to previous research by proposing a framework to study e-marketing strategy not only as an antecedent, but also as an outcome, of performance. Considering the rapid growth of e-commerce in our marketplace, there seems to be a need to assess what is really happening in the managerial world. We believe that marketing researchers generally are ignoring a significant part of the marketing-performance phenomenon. Research should consider two sets of relationships: Performance $\rightarrow$ E-Marketing effects and E-Marketing $\rightarrow$ Performance effects.

Future research should study not only the direct effects of contingent forces (i.e. internal and external forces) over performance, but also its indirect effects over performance through e-marketing strategies. Based on the contingency theory, future research may empirically test how the fit between e-marketing strategy and its context (whether organizational forces or external environment) impacts on performance. For example, one might suggest that in highly competitive markets an innovative organizational culture is required. In competitive environments firms have to constantly collect information about market competitors and environment, and as a result will have to be flexible, open to new ideas, and present quick decision making when implementing the web-strategy. On the other hand, in the less competitive environments the fact of having, or not, an innovative organizational culture might be irrelevant when implementing web-strategies. Hence, in addition to the analysis of the direct relationships, future research may empirically test the conceptual framework presented here. This will add to previous 
research by showing how the contingent forces (i.e. internal and external forces) affect

performance directly and indirectly, through their influence on the definition of the emarketing strategies. From the point of view of both firms and most national governments, the use of the Internet is extremely attractive because it reduces the firms' dependency on the domestic market, allows increased production through sales to foreign markets and consequently creates employment and enhances societal prosperity.

\section{REFERENCES}

Baker, W., M. Marn, and C. Zawada. 2001. "Price Smarter on the Net”, Harvard Business Review (Feb): 2-7.

Boulding, K. 1956. “General systems theory - The skeleton of science”. Management Science, 2, 197-208.

Bruner, G and A Kumar. 2000 "Web Commercials and Advertising Hierarchy of Effects", Journal of Advertising Research (April): 35-42.

Chakraborty, G., V. Lala, and W. David. 2002. "Important Factors in Business to Business Web Site Evaluation: A Scale Development Study.” In M. Evans and L. Sheer (eds.) Proceedings of the AMA Winter Conference.

Chen, Q. and W. Wells. 1999. “Attitude Towards the Site”, Journal of Advertising Research (Oct): 27-37.

Cyert, R. and J. March (1963), A behavioral theory of the firm. Englewood Cliffs, N.J.: Prentice-Hall.

Damanpour, Fariborz and William Evan. 1984. "Organizational Innovation and Performance: The Problem of Organizational Lag.” Administrative Science Quarterly, 29 (3): 392-409.

Day, George and Robin Wensley. 1988. "Assessing Advantage: A Framework for Diagnosing Competitive Superiority.” Journal of Marketing, 52 (Apr): 1-20.

De Geus, Arie. 1988. "Planning as Learning”. Harvard Business Review, 66 (March/April), 70-74.

Deshpandé, Rohit and John U. Farley (1996), "Understanding Market Orientation: A prospectively Designed Meta-Analysis of Three Market Orientation Scales”. Working Paper Series, Report 96-125. Cambridge, MA: Marketing Science Institute.

Dewar, Robert and James Werbel. 1979. "Universalistic and Contingency Predictions of Employee Satisfaction and Conflict”. Administrative Science Quarterly, 24 (September) 426-48.

Dutton, J. and R. Duncan. 1987. "The Creation of Momentum for Change Through the Process of Strategic Issue Diagnosis.” Strategic Management Journal, 8, 279-295.

Eisenhardt, Kathleen. 1989. "Making Fast Strategic Decisions in High-Velocity Environments.” Academy of Management Journal, 32 (Sep): 543-576.

Felton, Arthur. 1959. "Making the Marketing Concept Work”, Harvard Business Review, 37 (Jul/Aug), 5565.

Fredrickson, J. 1985. "Effects of Decision Motive and Organizational Performance Level on Strategic Decision Processes.” Academy of Management Journal, 28 (4): 821-43.

Glazer, Rashi and Allen Weiss. 1993. "Marketing in Turbulent Environment: Strategic Implications of Knowledge as an Asset.” Journal of Marketing, 55 (Oct): 1-19.

Grønhaug, Kjell and Geir Kaufmann. 1988. Innovation: A Cross-Disciplinary Perspective. Oslo, Norway: Norwegian University Press.

Han, Jin, Namwoon Kim, Rajendra Srivastava. 1998. "Market Orientation and Organizational Performance: Is Innovation a Missing Link?.” Journal of Marketing, 62 (4): 30-45.

Hofer, C. and Dan Schendel. 1978. Strategy Formulation: Analytical Concepts. St. Paul, MN: West Publishing Co.

Huber, George. 1991. "Organizational Learning: The Contributing Processes and the Literatures". Organization Science, 2 (February) 88-115. 
Jaworski, Bernard and Ajay Kohli. 1993. "Market Orientation: Antecedents and Consequences.” Journal of Marketing, 57 (Jul): 53-71.

Jennings, Devereaux and Paul Zandbergen. 1995. "Ecologically Sustainable Organizations: An Institutional Approach.” Academy of Management Review, 20 (4): 1015-1052.

Kemmler, Tilman et al, 2001. E-Performance II - The Good, the Bad, and the Merely Average. In mckinseyquarterly.com.

Kohli, Ajay and Bernard Jaworski. 1990. "Market Orientation: The Construct, Research Propositions, and Managerial Implications.” Journal of Marketing, 54 (Apr): 1-18.

Korgaonkar, P. and Wolin L. 1999. "A Multivariate Analysis of Web Usage.” Journal of Advertising Research, 39 (Mar-Apr): 53-68.

Lages, Luis Filipe and Cristiana Raquel Lages. 2004. "The STEP Scale: A Measure of Short-Term Export Performance Improvement”, Journal of International Marketing, 12(1): 36-56.

Lages, Luis Filipe, and David B. Montgomery. 2001. "The Effects of Prior Export Performance on Firm's Commitment to Exporting and Marketing Strategy Adaptation to the Foreign Market: Evidence from Small and Medium-Sized Exporters”, Research Paper 1701, GSB-Stanford University.

Lages, Luis Filipe, and David B. Montgomery. forthcoming, "Export Performance as an Antecedent of Export Commitment and Marketing Strategy Adaptation: Evidence from Small and Medium Sized Exporters.” European Journal of Marketing.

Lages, Luis Filipe. 2000. "A Conceptual Framework of the Determinants of Export Performance: Reorganizing Key Variables and Shifting Contingencies in Export Marketing.” Journal of Global Marketing, 13 (3): 29-51.

Lau, K, K. Lee, P. Lam, and Y. Ho. 2001. "Web Site Marketing for the Travel and Tourism Industry." Cornell Hotel and Restaurant Administration Quarterly, 42 (Dec): 55-62.

Lawrence, Paul and J. Lorsch. 1967. Organization and Environment: Managing Differentiation and Integration. Boston: Division of Research Graduate School Business Administration, Harvard University.

Lawton, Leigh and Parasuraman 1980. "The Impact of the Marketing Concept on New Product Planning.” Journal of Marketing, 44 (Winter): 19-25.

March, James, and H. Simon 1958. Organizations. New York: John Wiley \& Sons.

March, James, and Robert Sutton. 1997. "Organizational Performance as a Dependent Variable". Organization Science, 8 (6): 698-706.

Miller, Danny. 1987. "The Structural and Environmental Correlates of Business Strategy." Strategic Management Journal, 8 (Jan/Feb): 55-76.

Mintzberg, Henry 1979. The Structuring of Organizations. Englewood Cliffs, NJ: Prentice-Hall.

Narver, John and Stanley Slater. 1990. "The Effect of a Market Orientation on Business Profitability." Journal of Marketing, 54 (Oct) 20-35.

Picolli, G., B. Spalding, and B. Ives. 2001. "The Customer Service Lifecycle: A Framework for Improving Customer Service Through Information Technology.” Cornell Hotel and Restaurant Administration Quarterly, 42 (3): 38-45.

Pitt, L, P Berthon, R Watson, and M Ewing. 2001. "Pricing Strategy and the Net." Business Horizons, (Mar/Apr): 45-54.

Selnes, Fred, Bernard Jaworski, and Ajay Kohli. 1997. "Market Orientation in US and Scandinavian Companies: A Cross-Cultural Study". Marketing Science Institute Working Paper No 97-107. Cambridge, MA: Marketing Science Institute.

Simon, H. (1957). Administrative Behavior. New York: McMillan.

Sinkula, James 1994. "Market Information Processing and Organizational Learning." Journal of Marketing, 58 (Jan): 35-45.

Stevenson, Julie, Gordon Bruner II, Anand Kumar. 2000. "Webpage Background Viewer Attitudes." Journal of Advertising Research, 40 (Jan): 29-34.

Strauss, J. and R. Frost (2001) E-marketing, $2^{\text {nd }}$ ed, Prentice-Hall, New Jersey.

Supphellen, M. and H. Nysveen. 2001. "Drivers of Intention to Revisit the Web Sites of Well-Known Companies: The Role of Corporate Brand Loyalty.” International Journal of Market Research, 43 (3): 341-352.

Von Bertalanffy, L. 1951. General system theory: A new approach to unity of science. Human Biology, 23 (December), 303-61. 
Walker, Orville and Ruekert, Robert. 1987. “Marketing's Role in the Implementation of Business Strategies: A Critical Review and Conceptual Framework.” Journal of Marketing, 51 (Jul): 15-33.

Wyner, G. 2000. "Learn and Earn Through Testing on the Internet.” Marketing Research, 12 (3): 37-38.

Zaltman, Gerald, Robert Duncan, and Jonny Holbek. 1973. Innovations and Organizations New York: John Wiley and Sons.

Zeithaml, V. A., P. Varadarajan, and C. P. Zeithaml. 1988. "The Contingency Approach: Its Foundations and Relevance Theory Building and Research in Marketing”, European Journal of Marketing, 22(6): 37-64. 